\title{
Comparison of students' thinking processes when studying with WWW, IMM, and text based materials
}

\author{
L. Henderson, I. Putt, D. Ainge, and G. Coombs \\ School of Education \\ James Cook University of North Queensland \\ Townsville, Queensland, Australia \\ e-mail: Lynette.Henderson@jcu.edu.au
}

\begin{abstract}
This paper reports data obtained on the thinking of Bachelor of Education students as they interacted with World Wide Web (WWW) subject lecture material. The data were obtained from eight participating preservice teachers via stimulated recall interviews. The thinking (or mediating) processes engaged in during study sessions that related to the academic content of the WWW subject are detailed and discussed. The data are also compared with that obtained from an earlier comparative study of the thinking processes of two cohorts of inservice and preservice teachers: one group interacted with a professional development interactive multimedia (IMM) courseware package and the other with text based materials.
\end{abstract}

\section{Keywords}

Student thinking, WWW, Interactive multimedia, Stimulated recall interviews 


\section{INTRODUCTION}

A recent development in distributed learning environments involves the use of the WWW to deliver tertiary courses. Jacobson and Spiro (1995) and Oliver, Herrington, and Omari (1996) suggest that, because the Web allows browsing and thematic exploration, it facilitates higher order cognitive processes. However, despite the Web's ability to link learners instantaneously with its expanding and dynamic information base, the extent to which it promotes thinking skills and strategies is unknown. It is readily recognised that learning does not automatically occur as a direct result of the ever-increasing sophistication of computers and other educational technologies used for transmitting information. Rather, learning is related to the quality and quantity of thinking undertaken by learners (Litchfield, 1992) as they interact with computers as (un)intelligent tools (Jonassen and Reeves, 1996; Wild, 1995). That is, learning outcomes are a function of the thinking processes activated by instructional tasks and other learning activities.

Much existing research data regarding the efficacy of distributed learning environments is anchored in the process-product paradigm. The paradigm is based on the assumption that instructional stimuli give rise to learning outcomes and that students are mostly passive recipients of instructional strategies (Shulman, 1986). Recognition of the simplistic nature of this general cause effect paradigm when applied in the social sciences led to a fundamental reconceptualisation of research into teaching and learning materials used in flexible (or open) learning environments (Gibbs, Lockwood, Morgan, and Taylor, 1982; Marland, Patching, Putt, and Store, 1984; Parer, 1988). One such reconceptualisation favoured the adoption of the mediating process paradigm which focuses on student thought processes that mediate, or come between, instructional stimuli and learning outcomes. Mediating processes can be viewed as the fine grained elements of cognition through which, and by which, learning outcomes are realised.

A recent Australian study based on the mediating process paradigm focussed on mediating or thinking processes used by learners studying hard copy text (Marland, Patching, and Putt, 1992). Another investigation, that extended this work, was concerned with identifying the thinking processes activated by learners as they studied interactive multimedia (IMM) courseware materials (Putt, Henderson, and Patching, 1996). The current study builds on this previous work by identifying the thinking processes utilised by first year university students as they studied Web materials, and compares the data with that from the previous two studies. All three studies involved teacher education participants studying in a flexible learning mode. 


\section{METHODOLOGY}

Salomon (1991) describes the contrast between analytic research that is focused on isolating effective instructional treatments and systemic research focused on understanding how instructional treatments work in practice. This study embraced systemic research focussing on the sorts of thinking that tertiary students engaged in during study sessions with the WWW. As occurred with the IMM and text based materials investigations, the WWW study was guided by Reeves' (1995) and Salomon's (1991) pleas that the research context and methodology 'capitalize on authenticity' (Salomon, 1991, p. 16). The students' thinking processes were obtained in realistic, ecologically valid situations as the data were collected from students working in their regular study environment. Thus for the current study, data were gathered in a university setting on the eleventh WWW topic in week 12 of a 13 week semester. Conducting the research after the students had had numerous hours experience with the Web materials permitted minimalisation of any novelty effect. As well, even though the individual videotaped research sessions were of one half hour duration, the researchers felt that authenticity was kept because the subjects indicated that this was about the time that they would normally spend at one WWW study session anyway.

\section{Context and Participants}

A volunteer sample of eight preservice teachers was obtained from the cohort studying a compulsory first year education subject ED1441: Information Technologies in Education. This subject provides an introduction to the educational significance of current and future developments in information technologies. It includes the social and cognitive effects of information technologies and their relation to schooling; an analysis and design of various media texts; and applications and evaluation of media and computer technologies in education. The topic content studied during the videotaped study session covered social issues relating to technologies. It explored the effects of the Web, Internet, television, and video games on how we think and structure our world as well as the various ways in which these media are being dealt with in our changing world. The specific subsections that the Bachelor of Education students covered in their videotaped stimulated recall session were concerned with computer addiction, group interaction around computers, restricting access to unwanted material and to minors, software solutions, sexually explicit material on the internet, anonymity, privacy and security issues, and video game and television violence issues. There were five females and three males with ages ranging from 18 to 43 years. One was a recent graduate from high school, five had undertaken post secondary study, and two had been away from study for $20+$ years. Their computer experience ranged from that of complete novice to one possessing a technical qualification and substantial years of experience in the field of computers. They were in either their first or second semester of a four year Bachelor of Education degree. 


\section{Data Collection}

Data were collected on two categories of participants' thinking: (a) mediating processes generated as a result of interacting with the content of the WWW courseware and (b) evaluative thoughts about the instructional design features of the WWW materials. The focus in this paper is on a comparison of the results for category (a) with those reported in previous studies by Marland et al. (1992) and Putt et al. (1996).

In the WWW study the design parameters reflected those associated with the previous investigation of mediating processes used by learners studying from IMM courseware (Putt et al., 1996). A process-tracing approach was adopted and followed the strict guidelines developed over long experience with the stimulated recall technique (see guidelines in Marland, 1984; Marland et al., 1992). The interviewer and each participant together viewed a videotape of the study session. The split screen video records of the student's non verbal behaviours and the computer screen contained cues that stimulated each participant's recall of their mediating processes. Based on what occurred in the video, it was the interviewer's role to facilitate the participant's recall and verbalization of their thinking while studying the content of the mixed intranet/internet WWW courseware. The eight stimulated recall interviews, each of about one and a half hours duration, were conducted immediately following each video session and were audio taped for later transcription and analysis.

\section{DATA ANALYSIS AND RESULTS}

The interview transcripts from which the participants' mediating processes were identified were analyzed by pairs of the authors. Data from each pair were then compared, and, where disagreements occurred, consensus was achieved through group discussion. Data analysis proceeded according to the following steps.

1. Transcript data that were considered invalid (for example, thoughts that occurred during the interview but not during the study session or as a result of a leading question from the interviewer) were identified and discarded so that they would receive no further consideration.

2. The remaining transcript data were analyzed to identify reported instances of student thinking that occurred while studying the WWW course content.

3 . These instances of individual mediating processes reported by participants were classified according to the definitions used by Marland et al. (1992) and Henderson (1997). Table 1 contains mediating processes found in the current study together with descriptions from the Marland et al. (1992) and Henderson (1997) studies and examples taken from the present study. 


\begin{tabular}{|c|c|c|}
\hline Type & $\begin{array}{l}\text { Description } \\
\text { Mental activity in which a student: }\end{array}$ & Example \\
\hline Affect & reports feelings aroused by content during study & $\begin{array}{l}\text { 'This is really quite frustrating 'cause I want to } \\
\text { know so much more quickly than I do.' }\end{array}$ \\
\hline Anticipation & $\begin{array}{l}\text { predicts or states expectations that problem, question, } \\
\text { or textual feature will be encountered; looks forward to } \\
\text { new unit, material; wonders about: the possibility of an } \\
\text { event, occurrence in text, relevance of material, } \\
\text { content }\end{array}$ & $\begin{array}{l}\text { 'I thought, oh, we'll probably touch on some of } \\
\text { the material in previous tutes particularly, and } \\
\text { might enlighten me about a few issues that } \\
\text { weren't covered in the readings.' }\end{array}$ \\
\hline Categorisation & sorts items, ideas, skills into different groups, classes & $\begin{array}{l}\text { 'It was similar to everything I've learned so far. } \\
\text { White, middle class domination as per usual.' }\end{array}$ \\
\hline Comparison & $\begin{array}{l}\text { identifies similarities, differences between two } \\
\text { statements, concepts, models, situations, ideas, } \\
\text { theories, points of view, etc. }\end{array}$ & $\begin{array}{l}\text { 'This satanic impulse sort of thing I was } \\
\text { relating to my own Christian views.' }\end{array}$ \\
\hline Confirmation & $\begin{array}{l}\text { judges that ideas in text support one's own beliefs, } \\
\text { practices, tactics }\end{array}$ & $\begin{array}{l}\text { 'I agree with parents having a lot of control } \\
\text { over what their children have access to.' }\end{array}$ \\
\hline Deduction & $\begin{array}{l}\text { reasoning process by which a specific conclusion } \\
\text { necessarily follows from a set of general premises; } \\
\text { uses a logical progression of thought }\end{array}$ & $\begin{array}{l}\text { '... I was thinking they've really constructed } \\
\text { that and culturally defined it because ... what is } \\
\text { erotic in one culture is very different from what } \\
\text { is erotic or unacceptable in another.' }\end{array}$ \\
\hline Deliberation & $\begin{array}{l}\text { engages in 'thinking' about a topic, prose segment, etc. } \\
\text { (type of thinking not disclosed) }\end{array}$ & $\begin{array}{l}\text { 'How the graphics seemed to be virtually } \\
\text { aimed at children.' }\end{array}$ \\
\hline Diagnosis & $\begin{array}{l}\text { identifies strengths and weaknesses in idea, strategies, } \\
\text { points of view }\end{array}$ & $\begin{array}{l}\text { 'It's great that they're doing this, but it needs to } \\
\text { be more effective.' }\end{array}$ \\
\hline Evaluation & $\begin{array}{l}\text { makes judgments about the value, worthwhileness of } \\
\text { textual materials, activities, in-text questions, own } \\
\text { position or point of view }\end{array}$ & $\begin{array}{l}\text { 'I didn't agree with him.' } \\
\text { 'Well, it's probably one of the more } \\
\text { controversial things; that's what I was thinking } \\
\text { about.' }\end{array}$ \\
\hline Generating & $\begin{array}{l}\text { formulates one's own questions, examples, ideas, or } \\
\text { problems; interpolating; going beyond the data }\end{array}$ & $\begin{array}{l}\text { 'How in the hell, like, it's not going to be like } \\
\text { the club or anything. It's not going to be as } \\
\text { personal so I can't see how people can get the } \\
\text { kicks out it, it's just a screen; it's a glass } \\
\text { screen.' }\end{array}$ \\
\hline Imaging & $\begin{array}{l}\text { creates a mental image of an idea in text in order to } \\
\text { gain a fuller understanding }\end{array}$ & 'What I was reading I was visualising.' \\
\hline Justification & $\begin{array}{l}\text { tries to prove that a proposed action/idea is reasonable } \\
\text { or correct through argument }\end{array}$ & $\begin{array}{l}\text { 'I was only coming from my own personal } \\
\text { experience. I've got lots of cousins and } \\
\text { nephews and nieces.' }\end{array}$ \\
\hline Linking & $\begin{array}{l}\text { associates or brings together two or more ideas, topics, } \\
\text { contexts, headings, personal experiences, materials, } \\
\text { tasks }\end{array}$ & $\begin{array}{l}\text { 'Well the fact that even with my own wife, I } \\
\text { believe she has very much the norm attitude.' }\end{array}$ \\
\hline Metacognition & $\begin{array}{l}\text { thinks about, reflects on, evaluates or directs own } \\
\text { thinking }\end{array}$ & $\begin{array}{l}\text { 'I had to keep going back over because I didn't } \\
\text { understand the definition' } \\
\text { 'I haven't got a sort of concept map of how it } \\
\text { all works.' }\end{array}$ \\
\hline Recall & $\begin{array}{l}\text { brings back into working memory an idea, opinion, } \\
\text { fact previously stored in long term memory }\end{array}$ & $\begin{array}{l}\text { 'That reminded me about something that I had } \\
\text { read.' }\end{array}$ \\
\hline Reflection & $\begin{array}{l}\text { general indication of careful consideration or thought } \\
\text { over past action and response; tries to establish the } \\
\text { reason or causal link between the action and its } \\
\text { response; often stimulates considered action }\end{array}$ & $\begin{array}{l}\text { 'I was feeling really uncomfortable. Not so } \\
\text { much from the content of the material ... If I } \\
\text { hadn't seen it my whole attitude to this may } \\
\text { have been very different.' }\end{array}$ \\
\hline Selection & $\begin{array}{l}\text { identifies key material, gist material, or that which is } \\
\text { relevant to assessment }\end{array}$ & $\begin{array}{l}\text { 'I thought what I was reading there might be } \\
\text { pertinent to the topic so I just took it down.' }\end{array}$ \\
\hline $\begin{array}{l}\text { Strategy } \\
\text { Planning }\end{array}$ & $\begin{array}{l}\text { plans ways of processing or handling content material } \\
\text { during study sessions }\end{array}$ & $\begin{array}{l}\text { 'I thought I'd read basic text chunk first and go } \\
\text { from the top.' }\end{array}$ \\
\hline Translation & expresses segments of text in one's own words & $\begin{array}{l}\text { 'They've put down what children at various } \\
\text { ages get from the television and then they talk } \\
\text { about toddlers imitating what they see.' }\end{array}$ \\
\hline
\end{tabular}

Note: Descriptions are adapted from Marland et al.(1992) and Henderson (1997).

Table 1 Mediating processes identified in the present study 
Examples are from the current study

Data on mediating processes while studying the $W W W$ courseware

Mediating processes data resulting from the eight stimulated recall interviews were coded according to the procedure outlined above and frequencies for each type of mediating process reported by the participants were tallied (Table 2). A total of 287 mediating processes were identified from the interactive data in the transcripts. The mean number of reported mediating processes per person was 36 . This provides an interesting comparison with the other two studies where only 13 reported mediating processes per person were identified for students studying with the IMM materials but 28 for those learning with the text based materials.

The data in Table 2 indicate a wide variation in the frequency of occurrence of the 19 identified mediating processes. These ranged from $0.03 \%$ for 'reflection' to $26.5 \%$ for 'evaluation.' This variation in occurrence of the 19 mediating processes is displayed in Table 3. The frequency of occurrence is divided into four levels, namely, very high, high, low, very low which are the same frequency bands used in the Marland et al. (1992) and Putt et al. (1996) studies. In these studies, the $3 \%$ and $10 \%$ cutoff figures were arbitrarily chosen, whereas $5.3 \%(100 \div 19)$ was the average percentage frequency across all 19 categories found in the Marland et al. (1992) study.

Table 2 Frequency of mediating processes relating to academic content

\begin{tabular}{lcc}
\hline$a_{\text {Mediating Process }}$ & Total $(\boldsymbol{n}=8)(\%)$ \\
\hline Evaluation & 76 & $(26.5)$ \\
Linking & 33 & $(11.5)$ \\
Generating & 29 & $(10.1)$ \\
Metacognition & 27 & $(9.4)$ \\
Affective & 27 & $(9.4)$ \\
Strategy Planning & 22 & $(7.7)$ \\
Confirming & 13 & $(4.5)$ \\
Diagnosis & 9 & $(3.1)$ \\
Justification & 9 & $(3.1)$ \\
Deliberation & 8 & $(2.8)$ \\
Imaging & 7 & $(2.4)$ \\
Comparing & 6 & $(2.1)$ \\
Selection & 5 & $(1.7)$ \\
Anticipation & 4 & $(1.4)$ \\
Deducing & 4 & $(1.4)$ \\
Recalling & 3 & $(1.0)$ \\
Categorisation & 3 & $(1.0)$ \\
Translation & 1 & $(0.03)$ \\
Reflection & 1 & $(0.03)$ \\
\hline Total & 287 & $(100.0)$ \\
\hline Mean number of mediating processes per person & 36 & \\
\hline \multicolumn{2}{l}{ a based on responses from 8 participants }
\end{tabular}


In Table 3, three mediating processes, namely, evaluation, linking, and generating, have the highest frequencies in the WWW study. Two of these, evaluation and linking, also rated as very high in the IMM and text based studies. While generating rated as very high in the current study, it rated as high in the IMM study and low in the text based study. Three additional comparisons are worthy of note. Metacognition was high in the WWW study but very high in the other two. Whereas strategy planning rated as high in the present study, it rated low in the IMM study and very high in the text based study. On the other hand, 'anticipation' was very low in the present study but high in both of the other studies.

Table 3 Mediating processes grouped according to frequency range

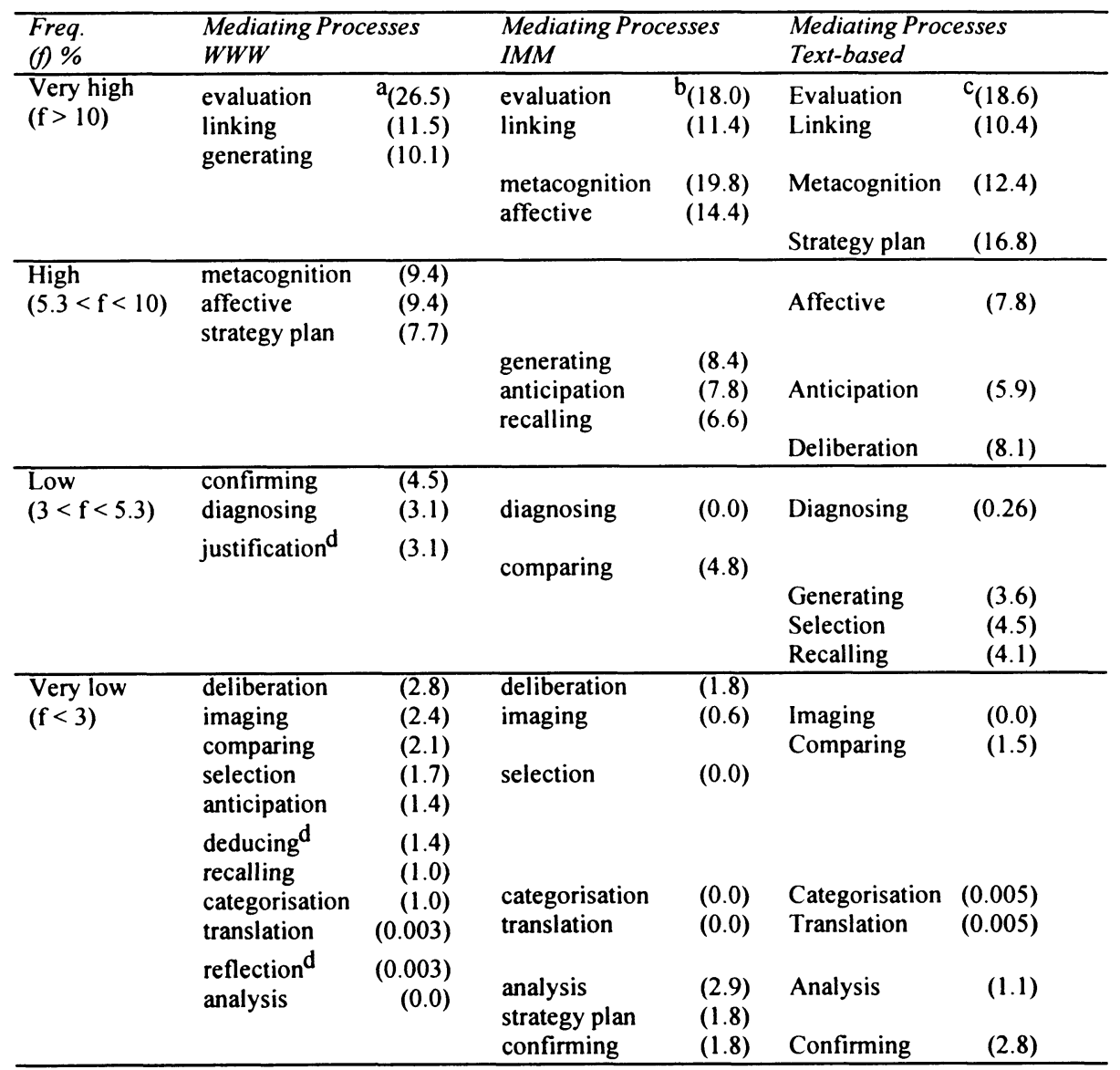

${ }^{\mathrm{a}}$ The number in parentheses is the percentage frequency.

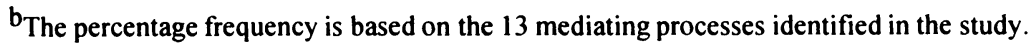

${ }^{\mathrm{c}}$ The percentage frequency is based on the 19 mediating processes identified in the study. dThese mediating processes were identified in the Henderson (1997) study. 


\section{DISCUSSION}

This section involves an interpretation of the data on the thinking processes elicited and discusses those mediating processes that displayed significant variation between the three studies.

\section{Mediating Processes}

On the surface Clark's (1994) contention that the medium is not the crucial variable in learning outcomes seems to be under challenge by the differences in the mean number of reported mediating process per student between the three studies: 36 , 13 , and 28 for students studying with the WWW, IMM, and text based materials, respectively. However, this does not seem to be the reason in this particular case. The data in the WWW and text based studies were collected from participants working individually but the IMM participants studied, and were interviewed, in their self-selected groups of two, three or four. It appears that the group situation could have allowed a participant to disengage from thoughtful participation in both, or either of, the study session and the stimulated recall interview. As well it may have suppressed the verbalisation of a participant's thoughts.

The very high percentage $(26.5 \%)$ of reported evaluative thoughts about the content of the WWW topic is more than twice that of the next highest ranking mediating process, linking $(11.5 \%)$. It is also a third higher than the evaluative thoughts tabulated for the IMM and text based studies (Table 3). Evaluation is defined as the mental process in which a judgement is made about the value or worth of some aspect of the content of the instructional material. All three studies contained material that was contentious and challenged the students' current practices, thus suggesting that all three studies should have had similar percentages. The IMM study concerned with social justice issues asked the learners to question their own attitudes and classroom practices with respect to racism and other inequities. The text based content presented factors influencing curriculum design that seriously questioned the status quo by offering seemingly radical ideas. A major focus of the WWW topic problematized the access and effect issues concerning gender, equity, rights, and morality in the censorship-violencepornography debate about Web content material. It seems plausible to argue that it was the nature of this type of content in the WWW topic that produced the percentage discrepancy. It also challenged many of the students' current perceptions by exposure to the research literature. For instance, most students believed there is a direct correlation between television and video game violence and child and adult violence in society, and found it difficult to rework their simplistic cause effect views.

Linking is defined as the process of associating, or bringing together in the mind, two or more ideas, topics, contexts, personal experiences, words, and so forth. Linking usually occurred when an item (e.g., text, graphic, or cartoon that illustrated a concept) prompted recall of an associated item in a participant's memory. It is noteworthy that linking had similar percentage frequencies in all three studies. This is not surprising given that all three sets of materials challenged 
participants to consider how the information related to their own and peers' beliefs, values and experiences.

Generating encompasses one or more of the following: (a) formulation of one's own questions, examples, ideas, opinions, problems, and answers; (b) interpolation by adding new knowledge through the elaboration of existing knowledge within a given framework; and (c) extrapolation which adds new knowledge by extending an existing framework and going beyond the data (Marland et al., 1992). Why then, given the characteristics of the participants and the nature of the content in the three studies, did the percentage frequency of generating mediating processes increase from text based (3.6\%), to IMM (8.4\%), to WWW $(10.1 \%)$ ? The most likely reason for the comparatively low percentage for learning with texts is that these participants were identified as assessment driven (Marland et al., 1992). They therefore allocated little time to going beyond what they deemed necessary to accomplish their assessment goals. The comparability of the percentages for the WWW and IMM studies could be attributed to the lack of embedded assessment in the materials and the provocative nature of the content. The latter reason would also help explain why the figure was slightly higher for the WWW.

Mediating processes classified as 'metacognition' are those in which students reported awareness of, reflecting on, evaluating, or directing their own thinking. This definition reflects a widely accepted view of metacognition as referring to students' knowledge about, and control over, their cognitive processes (Weinstein and Mayer, 1986). Even though metacognitive processes were high in the WWW study, they were approximately $50 \%$ of those reported for the IMM and $75 \%$ for the text based studies. This is a significant comparative difference given the importance of metacognitive strategies in successful tertiary study. This could be due to the quantity of information processed in the WWW study which was considerably larger than that covered in IMM or text for the equivalent half hour videotaped sessions. This suggests that information overload was probably a contributing factor. As well, it left fewer cognitive resources for monitoring their own thinking. These results reflect the fact that as novice tertiary students, the WWW participants had not yet fully learnt the strategies of, and necessity for, metacognitive practices.

Strategy planning refers to thought processes in which students plan ways of processing or handling instructional material or activities during study sessions. The percentage frequency in the present study is approximately four times that in the IMM study but only $46 \%$ of that for the text based study. One explanation given by Putt et al. (1996) for the very low frequency in the IMM study was the linear sequence suggested by the instructional designer for studying the five units in the IMM package - Social Justice Explored (White, 1993). Students did not appear to negotiate individual pathways through the materials and therefore did not spend time thinking about how they would process the materials but instead just followed the sequence. Furthermore, this IMM package did not include any assessment which might otherwise be likely to lead students to plan carefully how they would process the content. 
In contrast, both the WWW and text based materials, while still having linear content menus, allowed students more scope to choose different ways to navigate through the material. Nevertheless, the frequency for the WWW material is less than half that for the text based material; this is in spite of the fact that the WWW subject had a hypertext/hypermedia environment which was conducive to maximum choice of processing. A close look at the particular participants involved in the two studies gives some insight into the reasons for this marked difference in strategy planning between the two. One possible explanation is that the inservice teachers in the text based study were all experienced learners whilst the preservice teachers in the WWW study could be regarded as novice tertiary learners. A second explanation is that the text based materials had embedded assessment items which influenced the way the students processed the materials (Marland et al., 1992). These students generally viewed the objectives of the unit, then looked at the assessment for the unit and determined which materials were necessary to complete that assessment. They next planned to cover this essential material in the most time efficient way. In comparison, there was no embedded assessment within the WWW topic which may have functioned as a similar focussing device.

Anticipation is synonymous with prediction, looking forward to, speculation about, and expectations concerning the likelihood of encountering problems, types of content, and features of the medium. The very low rating for anticipation in the WWW study is arresting in light of its high rated frequency in the other two studies. Indeed, there were 5.5 times and 4.5 times more anticipatory thought processes reported in the IMM and text based studies, respectively. A possible explanation for this disparity is linked to the volume of content covered in the distributed learning environment of the WWW where students could continue exploring live links ad nauseam. Subsequently, they may have found it difficult and/or of little consequence to anticipate what content might emerge.

\section{CONCLUSION}

The authors argue that the Web should be used as a cognitive tool to enhance thinking, problem solving, and learning. To attain this goal, the study highlights two major implications for the instructional design of WWW materials.

First, it draws attention of instructional designers to the existence, types, and relative frequencies of mediating processes in which students engage while interacting with the WWW distributed learning environment (and that of IMM and text based materials). Second, there is a need for instructional designers to plan educational materials that will activate desired mediating processes as part of student learning. This is related to initial evidence that suggests instructional designers can actually engineer presentations to increase or decrease rates of occurrence of selected mediating processes. (See previous comments about the different rates of occurrence of strategy planning between the three studies.)

One approach that could be incorporated in WWW design is to make explicit the thinking processes the students could use to engage with the content satisfactorily. 
For example, Henderson, Patching, and Putt (1994) have been able to activate metacognition by the use of embedded prompts and interactions in university level IMM materials. We argue that this is an area that requires more attention by instructional designers and researchers.

\section{REFERENCES}

Clark, R. E. (1994) Media will never influence learning. Educational Technology Research and Technology, 42(2), 21-29.

Gibbs, G., Lockwood, F., Morgan, A., and Taylor, E. (1982) Student learning and course design 1: In-text teaching devices in Open University texts (Study Methods Group Report No. 12). Open University, Milton Keynes.

Henderson, L., Patching, W., and Putt, I. (1994) The impact of metacognitive interactive strategies and prompts embedded in interactive multimedia in a cross-cultural context: An exploratory investigation. In OPEN LEARNING '94, Proceedings of the 1st International Conference on Open Learning, (pp. 181186). Queensland Open Learning Network and The University of Queensland, Brisbane, Australia.

Henderson, M. (1997) Multimedia Interactivity: An investigation into learners' mediating processes during click-drag activities. B.Ed. (Hons) thesis. James Cook University, Townsville.

Jacobson, M., and Spiro, R. (1995) Hypertext learning environments, cognitive flexibility and the transfer of complex knowledge. Journal of Educational Computing Research, 12(4), 301-333.

Jonassen, D. H., and Reeves, T. C. (1996) Learning with technology: Using computers as cognitive tools. In Handbook of research for educational communications and technology (ed. D. H. Jonassen), (pp. 693-719). Macmillan, New York.

Litchfield, B. C.(1992) Evaluation of inquiry-based science software and interactive multimedia programs. Computing Teacher, 19(6), 41-43.

Marland, P. W. (1984) Stimulated recall from video: Its use in research on the thought processes of classroom participants. In Video in higher education (ed. O. Zuber-Skerrit), (pp. 156-165). Kogan Page, London.

Marland, P. W., Patching. W. G., and Putt, I. J. (1992) Learning from text: Glimpses inside the minds of distance learners. James Cook University of North Queensland, Townsville.

Marland, P. W., Patching, W. G., Putt, I. J., and Store, R. E. (1984) Learning from distance-teaching materials: A study of students' mediating responses. Distance Education, 5(2), 71-91.

Oliver, R., Herrington, J., and Omari, A. (1996) Creating effective instructional materials for the World Wide Web. In Proceedings of AusWeb96: The second Australian World Wide Web Conference (ed. M. Nott), Southern Cross University, Gold Coast, Australia. 
Parer, M. S. (1988) Textual design and student learning. Gippsland Institute of Advanced Education, Churchill, Victoria.

Putt, I., Henderson, L., and Patching, W. (1996) Teachers' Thinking Elicited from Interactive Multimedia Professional Development Courseware. Educational Technology Research and Development, 44(4), 7-22.

Reeves, T. C. (1995) Questioning the questions of instructional technology research. Proceedings of the Annual Conference of the Association for Educational Communications and Technology, Research and Theory Division (pp. 459-470). Association for Educational Communications and Technology, Research and Theory Division, Anaheim 9, CA.

Salomon, G. (1991) Transcending the qualitative-quantitative debate: The analytic and systemic approaches to educational research. Educational Researcher, 20(6), 10-18.

Shulman, L. S. (1986) Paradigms and research programs in the study of teaching: A contemporary perspective. In Handbook of research on teaching (ed. M. C. Wittrock), (3rd ed.), (pp. 3-36). Macmillan, New York.

Wild, M. (1995) Empowering learners: Using computers as cognitive tools. In Changes in the learning environment (ed. D. Thiele), (CD-ROM), (pp. 59-70). Open Learning Technology Corporation, Adelaide. Also available on-line at: [http://www.oltc.edu.au/oltpd/docs/inv01.html].

White, B. (1993) Social justice explored [CD-ROM]. Townsville: Queensland State Education Department.

\section{BIOGRAPHIES}

Lyn Henderson is senior lecturer at James Cook University of North Queensland, Australia. Her fields of teaching and research interests concern the cultural contextualization of instructional design of interactive multimedia (IMM) and the world wide web (WWW) offered in various flexible learning modes. Other research interests focus on the mental models, thinking processes, and teachinglearning strategies used by teachers and learners (from early childhood through tertiary in Australia and the United States) when interacting with each other and/or electronic databases, IMM, and the WWW.

Ian Putt is a senior lecturer in mathematics education at James Cook University, Townsville, Australia. He has been involved in teaching mathematics education courses at a distance via printed text to inservice teachers and through interactive multimedia (IMM) courseware to Aboriginal and Torres Strait Islander teacher education students in their home communities. His current research interests focus on tertiary students' thinking while studying with IMM and WWW materials and their usage patterns of such courseware. He also supervises post graduate students in the area of teaching problem solving in upper primary and lower secondary school. 
David Ainge is senior lecturer at James Cook University, Townsville, Australia. His current research interest, besides tertiary students' thinking processes of learning with the WWW, is on uses of virtual reality in schools. Virtual reality appears to have great potential for education, and my current research in primary schools is investigating its capacity to enhance: (a) active learning, particularly in hard-to-motivate students; (b) individual construction of learning; and (c) learning across a range of ability levels.

Geoff Coombs is a lecturer in social and cultural studies in education and the acting director of the Professional Experience Unit at James Cook University, Townsville, Australia. His current research and teaching interests include the ethnographic study of education and schooling and WWW instructional design. He also conducts professional development courses in creating WWW sites and developing effective web search strategies for school-based educators. 